\title{
Nadliczbowy siekacz w żuchwie — opis przypadku
}

\author{
Supernumerary lower incisor - a case report \\ 1 Studenckie Koło Naukowe Ortopedii Szczękowej i Ortodoncji, \\ Uniwersytet Medyczny im. Karola Marcinkowskiego w Poznaniu \\ ${ }^{2}$ Katedra i Klinika Ortopedii Szczękowej i Ortodoncji, \\ Uniwersytet Medyczny im. Karola Marcinkowskiego w Poznaniu
}

DOI: http://dx.doi.org/10.20883/df.2020.7

\begin{abstract}
STRESZCZENIE
Dokonano przeglądu piśmiennictwa dotyczącego występowania nadliczbowego siekacza w żuchwie wraz z przedstawieniem przypadku własnego, celem omówienia znaczenia i implikacji tej patologii w praktyce klinicznej. Przedstawiono przypadek własny pacjentki z nadliczbowym, niewyrzniętym siekaczem dolnym o zmniejszonych wymiarach, który był przyczyną stłoczeń, co skutkowało wdrożeniem terapii ekstrakcyjnej. W analizowanych pracach ponad połowa dodatkowych siekaczy w żuchwie posiadała prawidłową budowę i kształt oraz w większości przypadków była przyczyną niedoboru miejsca, stanowiąc wskazanie do ekstrakcji.
\end{abstract}

Słowa kluczowe: nadliczbowy siekacz żuchwy, nadliczbowe zęby.

\section{ABSTRACT}

The aim of this article was to report one own case of supernumerary lower incisors in non-syndromic patient and to discuss relevance and implications of this dental abnormality in clinical practice. The own case describes a woman with a supernumerary, unerupted tooth of reduced size, that caused crowding and resulted in implementation of extraction therapy. The study was supported by a literature review. The evaluation showed that more than a half of the supernumerary lower incisors had a proper structure and shape. These incisor-like supernumeraries caused most often a lack of space in dental arch and due to this fact became an indication for extraction.

Keywords: supernumerary lower incisor, supernumerary teeth.

\section{Wstęp}

Ząb nadliczbowy definiuje się jako ząb, który pojawia się dodatkowo $w$ prawidłowym uzębieniu. Występować może w każdym typie uzębienia, w dowolnym miejscu w jamie ustnej, pojedynczo lub mnogo. Częstość występowania tego zjawiska waha się między 0,1 a 3,8\%. Około $80 \%$ zębów nadliczbowych pozostaje niewyrzniętych [1]. Ząb nadliczbowy może przyjąć kształt typowy dla pewnej grupy zębów bądź nietypowy o odmiennej formie i kształcie. Najczęściej obserwowane jest występowanie mesiodensu, który zazwyczaj znajduje się w linii pośrodkowej górnego łuku zębowego. Zęby nadliczbowe przeważnie występują w szczęce w uzębieniu stałym [2]. Nadliczbowość w żuchwie $w$ rejonie zębów przedtrzonowych stanowi $7 \%$ przypadków, a w rejonie zębów trzonowych i siekaczy centralnych 2\% [1]. Scheiner i Sampson, opisując morfologię zębów nadliczbowych, wyróżnili budowę stożkowatą, guzkowatą, uzupełniającą i przyjmującą formę zębiaka. Dodatkowe zęby mogą być usytuowane policzkowo, podniebienie lub poprzecznie. Etiologia powstawania zębów nadliczbowych jest nie do końca poznana, ale wpływ na ich rozwój mogą mieć czynniki genetyczne bądź środowiskowe. Teoria dychotomii tłumacząca powstawanie tej anomalii mówi o tym, iż podczas tworzenia zarodka dochodzi do podziału pąka zęba na dwa zęby równej wielkości lub na jeden ząb prawidłowy i dysmorficzny. Kolejna teoria sugeruje, iż dochodzi do nadmiernej aktywności blaszki zębowej, skutkującej powstawaniem dodatkowych zawiązków zębowych. Istnieje również wiele badań wykazujących związek między czynnikami genetycznymi a rozwojem zębów dodatkowych. Zęby nadliczbowe mogą być również wy- 
nikiem zjawiska nawrotu (atawizmu), co świadczy o powrocie do bardziej prymitywnego uzębienia. Występowanie zębów nadliczbowych jest również łączone z jednostkami chorobowymi, takimi jak: dysplazja czaszkowo-twarzowa, zespół Gardnera, zespół Marfana, rozszczep wargi lub podniebienia [3].

\section{Opis przypadku}

Pacjentka lat 20 zgłosiła się do poradni Radus Stomatologia w celu poprawy estetyki uzębienia
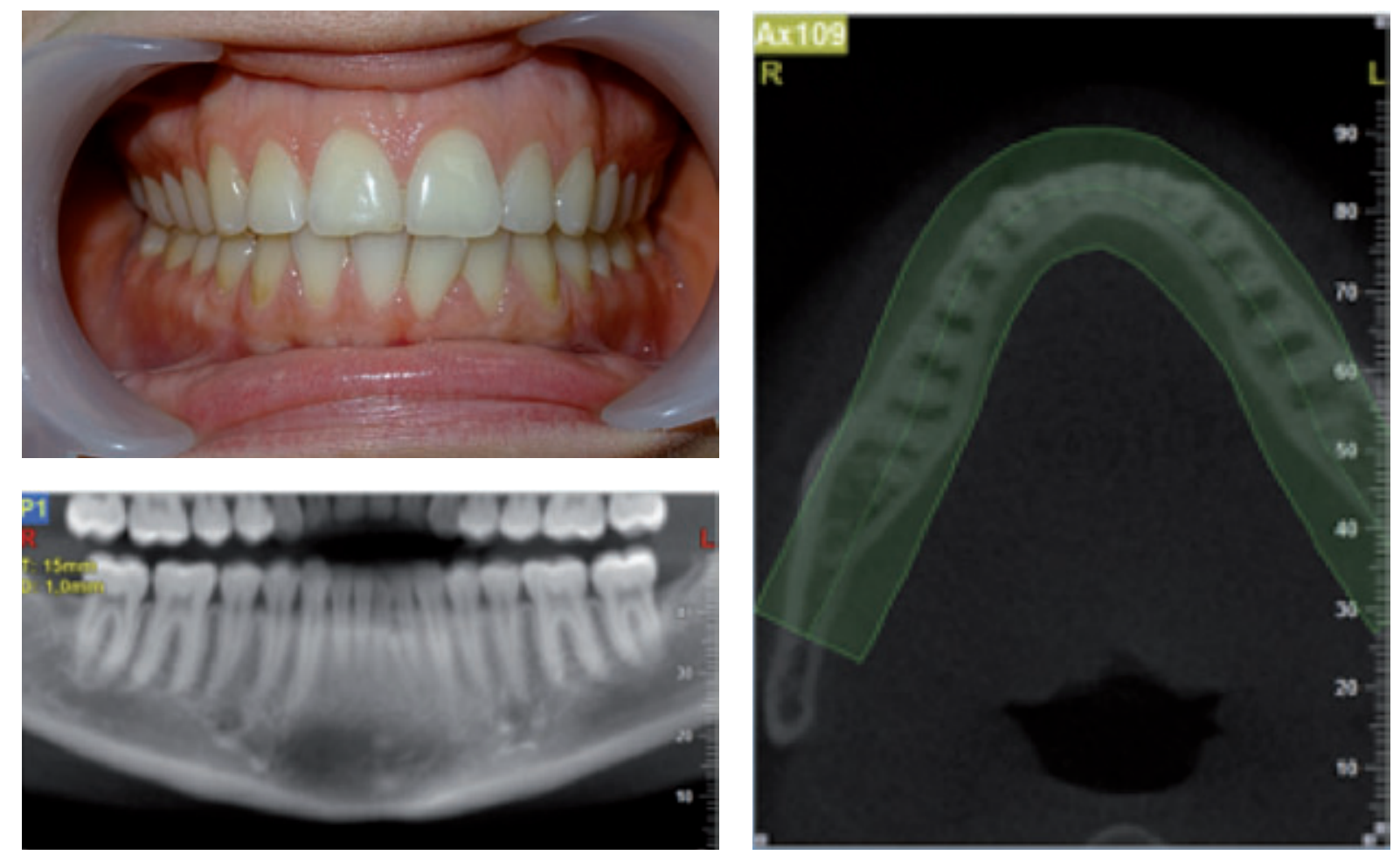

Rycina 1. Medyczna dokumentacja fotograficzna i radiologiczna

Figure 1. Medical photographic and radiological documentation
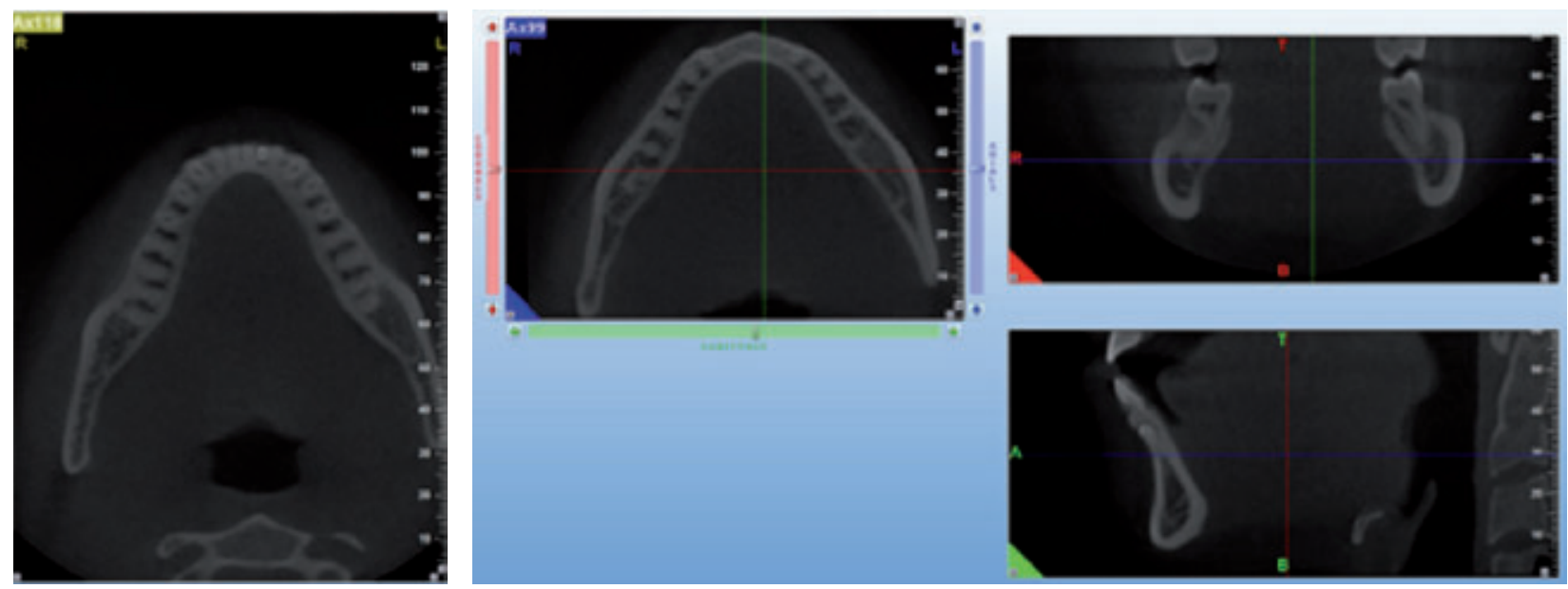

Rycina 2. Zdjęcie stożkowej tomografii komputerowej — płaszczyzna poprzeczna, strzałkowa

Figure 2. CBCT photo - transverse, sagittal plane 
kania oraz wtłaczanie języka między łuki zębowe. Higiena jamy ustnej pacjentki była dobra, dziąsła wykazywały tendencję do recesji. W badaniu radiologicznym na zdjęciu pantomograficznym uwidoczniono niewyrznięty ząb nadliczbowy w żuchwie $\mathrm{w}$ rejonie siekaczy (rycina 1 ). Wykonano dodatkowo badanie CBCT w celu dokładnej lokalizacji zęba dodatkowego - znajdował się on przedsionkowo i pomiędzy korzeniami siekaczy dolnych lewych, jego długość całkowita to ok. $10 \mathrm{~mm}$ (ryciny 2 i 3). Nie zaobserwowano resorpcji zębów sąsiadujących. Na podstawie przeprowadzonych badań diagnostycznych postawiono rozpoznanie: ząb nadliczbowy w żuchwie, klasa I Angle'a wraz z Il klasą kłową.

Dokonano przeglądu piśmiennictwa kazuistycznego (tabela 1), szukając artykułów w bazie internetowej PubMed Central, Google Scholar i Google, po wpisaniu hasła „supernumerary lo-

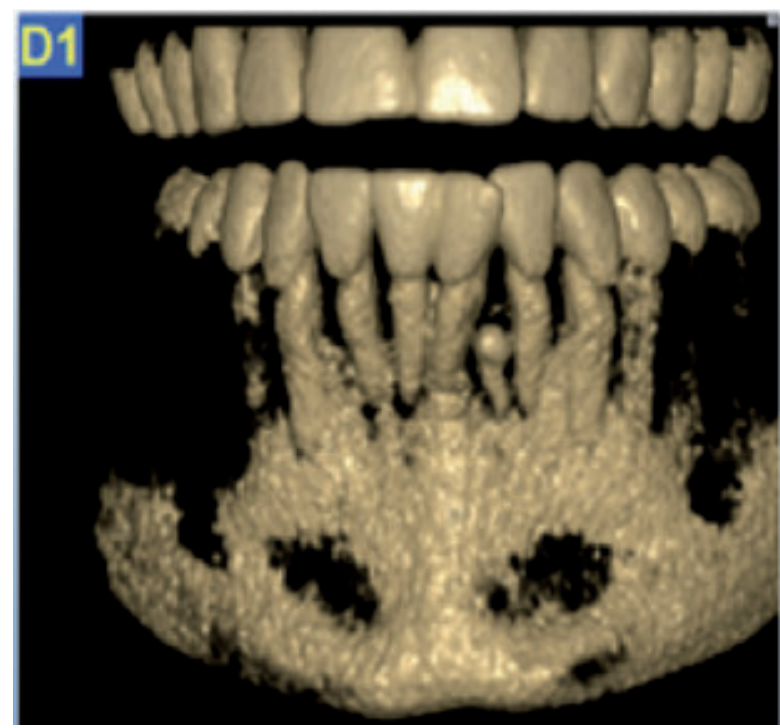

Rycina 3. Zdjęcie stożkowej tomografii komputerowej - model 3D

Figure 3. CBCT photo $-3 D$ model

Tabela 1. Zastawienie wybranych pozycji piśmiennictwa

Table 1. List of selected references

\begin{tabular}{|c|c|c|c|c|c|c|}
\hline Autor, rok & 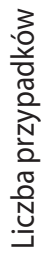 & 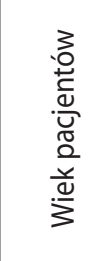 & $\begin{array}{c}\text { Płeć } \\
\text { pacjentów }\end{array}$ & 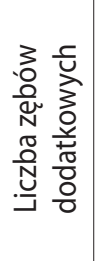 & $\begin{array}{l}\text { Czy siekacz miał } \\
\text { prawidłową budowę }\end{array}$ & $\begin{array}{l}\text { Czy występowało } \\
\text { miejsce w łuku dla } \\
\text { zęba dodatkowego }\end{array}$ \\
\hline Spyrymulos i wsp., 1979 & 1 & 16 lat & kobieta & 1 & tak & tak \\
\hline Scheiner i Sampson, 1997 & 1 & 11 lat & dziewczynka & 2 & nie & niewyrznięte \\
\hline Fukuta i wsp., 1999 & 5 & $\begin{array}{l}24 \text { lata } \\
22 \text { lata } \\
17 \text { lat } \\
40 \text { lat } \\
31 \text { lat }\end{array}$ & $\begin{array}{l}\text { mężczyzna } \\
\text { kobieta } \\
\text { dziewczyna } \\
\text { kobieta } \\
\text { kobieta }\end{array}$ & $\begin{array}{l}1 \\
1 \\
1 \\
1 \\
2\end{array}$ & $\begin{array}{l}\text { mniejszy } \\
\text { tak } \\
\text { mniejszy, korzeń krótszy } \\
\text { tak } \\
1 \text { ząb - tak, } 2 \text { ząb } \\
\text { o mniejszej koronie }\end{array}$ & $\begin{array}{l}\text { tak } \\
\text { tak } \\
\text { brak — rotacje zębów } \\
\text { brak - rotacje zębów } \\
\text { brak — rotacje zębów }\end{array}$ \\
\hline Katz i wsp., 2002 & 1 & 9 lat & chłopiec & 1 & nie & niewyrznięty \\
\hline Yokose i wsp., 2006 & 2 & $\begin{array}{l}16 \text { lat } \\
13 \text { lat }\end{array}$ & $\begin{array}{l}\text { chłopiec } \\
\text { dziewczynka }\end{array}$ & $\begin{array}{l}1 \\
2\end{array}$ & $\begin{array}{l}\text { tak } \\
\text { tak }\end{array}$ & $\begin{array}{l}\text { brak — rotacje zębów } \\
\text { brak - rotacje zębów }\end{array}$ \\
\hline Bhat, 2006 & 1 & 13 lat & chłopiec & 1 & tak & brak - rotacje zębów \\
\hline Cho, 2006 & 2 & $\begin{array}{l}7 \text { lat } \\
9 \text { lat } \\
\end{array}$ & $\begin{array}{l}\text { dziewczynka } \\
\text { mężczyzna }\end{array}$ & $\begin{array}{l}1 \\
1\end{array}$ & $\begin{array}{l}\text { tak } \\
\text { tak }\end{array}$ & $\begin{array}{l}\text { brak - rotacje zębów } \\
\text { brak - rotacje zębów }\end{array}$ \\
\hline $\begin{array}{l}\text { Wędrychowska-Szulc } \\
\text { i Janiszewska-Olszewska, } 2007\end{array}$ & 2 & $\begin{array}{l}14 \text { lat } \\
10 \text { lat } \\
\end{array}$ & $\begin{array}{l}\text { chłopiec } \\
\text { dziewczynka }\end{array}$ & $\begin{array}{l}1 \\
1\end{array}$ & $\begin{array}{l}\text { tak, nieznacznie węższy } \\
\text { tak }\end{array}$ & $\begin{array}{l}\text { nie, ząb niewyrznięty } \\
\text { brak — rotacje zębów }\end{array}$ \\
\hline Grga i Dželetović, 2010 & 1 & 27 lat & mężczyzna & 1 & $\begin{array}{l}\text { nie - stożkowy, korona } \\
\text { pokryta do } 1 / 2 \text { szkliwem }\end{array}$ & brak - rotacje zębów \\
\hline Pithon, 2010 & 1 & 31 lat & kobieta & 1 & tak & tak \\
\hline Verma i wsp., 2010 & 1 & 25 lat & mężczyzna & 1 & tak & tak \\
\hline Naganahalli i wsp., 2013 & 1 & 34 lat & mężczyzna & 1 & tak & tak \\
\hline Kariya i wsp., 2014 & 1 & 11 lat & dziewczynka & 1 & tak & brak - rotacje zębów \\
\hline Gupta i Subramaniam, 2014 & 1 & 9 lat & chłopiec & 1 & tak & brak - rotacje zębów \\
\hline Natarajan i wsp., 2017 & 1 & 14 lat & dziewczynka & 1 & tak & brak - rotacje zębów \\
\hline Barreto i da Costa Santos, 2018 & 1 & 20 lat & kobieta & 2 & tak & brak - rotacje zębów \\
\hline Tsujino, i Shintani, 2019 & 1 & 7 lat & chłopiec & 1 & tak & zatrzymany \\
\hline
\end{tabular}


wer incisor" otrzymano kolejno: 819, 40 i 119000 wyników, z czego wybrano 17 do omówienia opisy przypadków z nadliczbowym siekaczem w żuchwie.

\section{Dyskusja}

Przegląd piśmiennictwa podaje 24 przypadki dodatkowych zębów siecznych w odcinku przednim żuchwy. W przeprowadzonym przez nas zestawieniu 19 zębów dodatkowych wykazywało budowę prawidłową, 2 zęby były mniejsze, 4 zęby pozostały niewyrznięte, 1 ząb miał kształt stożkowy i był pokryty do połowy szkliwem, a 1 ząb był zlany. 19 przypadków stanowią zęby sieczne o prawidłowej budowie, przypominające siekacz, co wśród zębów dodatkowych występuje tylko w około $1 / 5$ przypadków, zatem zjawiska tego w odcinku przednim żuchwy można spodziewać się częściej niż w innych okolicach $[4,6,8-11,13-$ 20]. Czterech pacjentów [5, 6, 8, 19] spośród cytowanych przypadków posiadało po 2 dodatkowe zęby, natomiast pozostałe osoby tylko 1 ząb. Występowanie dodatkowego siekacza w odcinku przednim żuchwy może przysporzyć problemów diagnostycznych ze względu na rzadki charakter zjawiska (1-2\% zębów nadliczbowych), a także stosunkowo częstą budowę przypominającą prawidłowy siekacz, co może być przyczyną błędów w komunikacji z chirurgiem. Istnienie zębów dodatkowych jest często powiązane z chorobami genetycznymi bądź zespołami chorobowymi, takimi jak rozszczep wargi lub podniebienia, dysplazja czaszkowo-twarzowa oraz zespół Gardinera [2], jednak w przypadku przytoczonym przez nas oraz przypadkach z przeglądu piśmiennictwa nie wykazano takiej korelacji [4-20]. Etiologia istnienia zębów nadliczbowych we wszystkich przypadkach pozostaje niejasna. Opisany przez nas przypadek kliniczny przedstawia pacjentkę z zębem dodatkowym, niewyrzniętym, o zmniejszonych rozmiarach, który spowodował stłoczenie w odcinku przednim żuchwy. Jak wynika z przeglądu piśmiennictwa łuki zębowe nie są w stanie pomieścić dodatkowego zęba - w 14 na 20 przypadków wystąpiło stłoczenie spowodowane niedoborem przestrzeni.

\section{Oświadczenia}

Oświadczenie dotyczące konfliktu interesów Autorzy deklarują brak konfliktu interesów w autorstwie oraz publikacji pracy.

Źródła finansowania

Autorzy deklarują brak źródeł finansowania.

\section{Piśmiennictwo}

[1] Rao PP, Chidzonga M.M. Supernumerary teeth: literature review. Cent AfrJ Med. 2001;47(I):22-6.

[2] Karłowska I. Zarys współczesnej ortodoncji. Diagnostyka wad zgryzu. Wydawnictwo lekarskie PWZL, Warszawa; 2008, s. 78-100.

[3] Mallineni S.K. Supernumerary Teeth: Review of the Literature with Recent Updates. Hindawi Publishing Corporation Conference Papers in Science. 2014;2014:1-6.

[4] Spyrymulos ND, Pumkns Al, Angelopo A.P. Simultaneous presence of partial anodontia and supernumerary teeth. Oral Surg. 1979;48(1):53-56.

[5] Scheiner MA, Sampson W.J. Supernumerary teeth: A review of the literature and four case reports. Aust Dent J. 1997;42(3):160-165.

[6] Fukuta Y, Totsuka M, Takeda Y, Yamamoto H. Supernumerary teeth with eumorphism in the lower incisor region: A report of five cases and a review of the literature. J Oral Sci. 1999;41(4):199-202.

[7] Katz J, Guelmann M, Barak S. Hereditary gingival fibromatosis with distinct dental, skeletal and developmental abnormalities. Pediatr Dent. 2002;24(3):253-256.

[8] Yokose T, Sakamoto T, Sueishi K, Yatabe K, Tsujino K, Kubo S, Yakushiji M, Yamaguchi H. Two Cases with Supernumerary Teeth in Lower Incisor Region. Bull Tokyo Dent Coll. 2006;47(1):19-23. .

[9] Bhat M. Supplemental mandibular central incisor. J Indian Soc Pedod Prev Dent - Special issue. 2006;5(24):20-23.

[10] Cho S.Y. Supplemental Mandibular Permanent Incisor Teeth: Report of Two Cases. Primary Dental Care. 2006;13(2):76-78.

[11] Wędrychowska-Szulc B, Janiszewska-Olszewska J. The supernumerary lateral incisors - morphology and concomitant. Roczniki Pomorskiej Akademii Medycznej w Szczecinie. 2007;53(3):107-113.

[12] Grga D, Dželetović B. Supernumerary Tooth in Lower Incisor Region: A Case Report. Serbian Dental Journal. 2010;57(4):220-222.

[13] Pithon M.M. Temporary paresthesia of the lower lip during traction of retained inferior premolar. Orthodontic waves. 2010;69:171-175.

[14] Verma V, Goel A, Sabir M. Supernumerary eumorphic mandibular incisor in association with aggressive periodontitis. J Indian Soc Periodontol. 2010;14(2): 136-138.

[15] Naganahalli M, Honnappa A, Chaitanya N. Supplemental Mandibular Mesiodens: A Diagnostic Challenge. J Clin Diagn Res. 2013;7(12):3077-3078.

[16] Kariya PB, Singh S, Arora A. A mandibular supernumerary supplemental incisor. BMJ Case Reports. 2014;2014:bcr2014204044.

[17] Gupta M, Subramaniam P. Supplemental Permanent Mandibular Incisor- A Rare Case Report. J Interdiscipl Med Dent Sci. 2015;1(3):163.

[18] Natarajan M, Rao B, Urala A.S. A case of five mandibular incisors. Dental update. 2017;8(44):787-792.

[19] Barreto FA, Da Costa Santos J.R. Virtual orthodontic setup in orthodontic camouflage planning for ske- 
letal Class III malocclusion. Dental Press J Orthod. 2018;23(2):75-86.

[20] Tsujino K, Shintani S. A case of supernumerary tooth in the mandibular anterior region - Report on a rare case of five mandibular incisors. Pediatric Dental Journal. 2019;2(29):105-109.

Zaakceptowano do edycji: 2020-06-01 Zaakceptowano do publikacji: 2020-06-15
Adres do korespondencji:

Katedra i Klinika Ortopedii Szczękowej i Ortodoncji

Uniwersytet Medyczny im. Karola Marcinkowskiego

w Poznaniu

ul. Bukowska 70, 60-812 Poznań

tel.: 618547068

e-mail: klinika.ortodoncji@ump.edu.pl 